\title{
Bazinga! Consumo e performance sobre The Big Bang Theory no Filmow
}

\author{
Sandra Portella Montardo \\ Doutora; Universidade Feevale, Novo Hamburgo, RS, Brasil \\ sandramontardo@feevale.br \\ Thaís Della Tôrres da Silva \\ Graduada; Universidade Feevale, Novo Hamburgo, RS, Brasil \\ thaisdellatorres@hotmail.com
}

\begin{abstract}
Resumo
Este artigo visa identificar consumo como performance da sitcom The Big Bang Theory no Filmow, site de rede social temático para aficionados por filmes e séries. Para tanto, o referencial teórico aborda, de modo articulado, as relações entre consumo digital, performance e sites de redes sociais temáticos, categorias de análise selecionadas para este estudo. Quanto à metodologia, essa pesquisa consiste em um nível de pesquisa exploratório, via levantamento bibliográfico, documental e aplicação de questionários junto aos usuários. A partir da análise de 698 comentários de usuários da página da sitcom, percebeu-se que, ao contrário do que se observa em sites de redes sociais generalistas, no Filmow, a estrutura do portal parece assegurar alocação de capital social de segundo nível (confiança no ambiente social e institucional), ao invés dos tipos de capital social de primeiro nível (cognitivo, relacional e normativo), que, nesse caso, advém das interações entre os usuários.
\end{abstract}

\section{Palavras-chave}

Consumo digital. Performance. Capital social. Filmow. The Big Bang Theory.

\section{Introdução}

Em um artigo anterior (MONTARDO; SILVA, 2015b), analisou-se o consumo como performance no site Filmow, focando-se nas questões de performance enquanto capital social entre os seus usuários a partir de conversações em torno do filme 12 Anos de Escravidão (2014). Nessa oportunidade, além da elaboração do levantamento do estado da arte sobre Filmow, identificou-se que atuações individuais e coletivas, por meio de 
postagens de texto, garantem a manutenção do grupo. Nesse sentido, funções da performance associadas à identidade e à comunidade, bem como tipos de capital social (relacional e confiança no ambiente social) foram localizadas em todas as manifestações dos usuários no período analisado.

Frente a isso, surgiu o interesse em saber como essas interações se dariam em relação a uma sitcom, que apresenta estrutura narrativa distinta de um filme, uma vez que é disposta em temporadas. Portanto, neste artigo o objetivo é analisar o consumo como performance no Filmow, nas interações sobre a sitcom The Big Bang Theory, que já conquistou diversos prêmios.

Como se configura o consumo como performance de The Big Bang Theory no site de rede social temático Filmow? Para que se responda a essa pergunta, é importante explicitar as categorias que serão empregadas na análise das interações que ocorrem nesse espaço, além de se diferenciar os conceitos de série, seriado e sitcom.

\section{Consumo e performance em sites de redes sociais temáticos}

De forma resumida, Barbosa (2009) argumenta que o consumo pode ser interpretado como uma categoria central para a definição da sociedade contemporânea por estar relacionado aos seguintes vetores: (1) variadas formas de provisão e de acessos a bens e serviços; (2) produção de sentido e de identidades, independentemente da aquisição de um bem; (3) fator de determinação de direitos, estilos de vida e identidades nos grupos sociais.

Campbell (2009), por sua vez, destaca o papel do consumo em confirmar ou criar identidade, já que, atualmente, desejos, interesses, gostos ou preferências definem mais claramente os indivíduos. Nesse sentido, seríamos definidos pelas nossas reações a bens e serviços e não pela simples posse ou uso dos mesmos.

Pode-se dizer que Pinheiro (2008) aplica esse entendimento de Campbell (2009) a sites de redes sociais, ao apontar que os perfis dispostos nesses espaços, normalmente, são compostos pela listagem de bens culturais consumidos e de atividades sociais preferidas. Com isso, percebe-se o indício de que muitas interações nesses espaços podem estar circunscritas à performance pelas sugestões de consumo inerentes às mesmas.

Dessas três abordagens, destaca-se que consumo, mesmo não se referindo, necessariamente, à aquisição de um bem, está associado à interação social e, por isso, ao 
processo de formação de identidade na contemporaneidade. 0 entendimento de performance em Ehrenberg (2010) guarda relação com esses pontos.

Frente à constatação de que a origem social que outrora depreendia da identidade passa a ser insuficiente para atribuir status ou visibilidade no contemporâneo, Ehrenberg (2010) conclui que a construção identitária passa a depender de um projeto voltado ao futuro, por meio de uma performance individual. Na medida em que "ser alguém" atualmente pressupõe ação de cunho pessoal, o autor flagra a relação inédita entre a identidade pessoal e a visibilidade social, e entre esta e a autenticidade.

Quanto ao conceito de performance de Schechner (2003), importa destacar a ideia de comportamento restaurado. Ser exibido e mostrar-se fazendo algo a alguém é como Schechner (2003) define o ato de performar. Segundo este autor, qualquer experiência constituinte do desenvolvimento humano, sejam elas práticas de arte, rituais ou da vida cotidiana, pode ser entendida como performance, tendo-se em vista a tendência de se viver de acordo com a cultura na qual estamos inseridos, o que pode ser compreendido em termos de comportamento restaurado. "O comportamento restaurado é - eu me comportando como se fosse outra pessoa, ou eu me comportando como me mandaram ou eu me comportando como aprendi." (SCHECHNER, 2003, p. 5). A Internet e a mídia contribuiriam, segundo o autor, para que se vivesse "sequências de performances conectadas", já que elas próprias produzem e reproduzem situações sociais.

Ainda, de acordo com Schechner (2003), há sete funções para a performance, que são:

a) entreter;

b) fazer alguma coisa que é bela;

c) marcar ou mudar a identidade;

d) fazer ou estimular uma comunidade;

e) curar;

f) ensinar, persuadir ou convencer;

g) lidar com o sagrado e com o demoníaco.

O autor enfatiza que estas funções não estão listadas em ordem de importância e que nenhuma performance exerce todas, ainda que muitas enfatizem mais de uma. Muito raramente uma performance focaliza uma única função, ou mesmo apenas duas, segundo Schechner (2003). 
Boyd (2007) adapta a perspectiva de Goffman (1975) quanto à preocupação por parte de quem representa em termos das impressões causadas nos outros a partir de intenções determinadas, às interações em sites de redes sociais. Para a autora, citada por Nascimento (2010), o controle sobre recursos de como comunicar, bem como a seleção dos tipos de informações a revelar fazem com que a performance nesses espaços seja mais facilmente gerenciável, ao interpretar os perfis como formas de performances virtuais identitárias.

Sites de redes sociais, então, são sistemas que permitem personalização, interação e exposição da rede de cada ator (BOYD; ELLISON, $2007^{1}$ apud RECUERO, 2009). Já sites de redes sociais temáticos podem ser definidos como aqueles projetados para sustentar a socialização em torno de um único tema (filmes, música, culinária, etc) (MONTARDO, SILVA, 2015a).

De acordo com Recuero (2009), a apropriação dos sites de redes sociais consiste na construção de valores conectados que, por sua vez, facilitam a percepção de capital social. Deve-se destacar que a relação entre consumo e performance, privilegiada nesta pesquisa, tem relação explícita com essa percepção de capital social conforme será exposto na análise.

Bourdieu $\left(1980^{2} ; 1986^{3}\right)$ e Coleman $\left(1987^{4} ; 1988^{5}\right)$ definiram capital social como um "[...] meio de sistematizar os efeitos das relações sociais." (apud CASTIGLIONE; VAN DETH; WOLLEB, 2008, p. 3). Para esses autores, a abordagem de Coleman reconcilia a ação do indivíduo com a estrutura social, de modo que a análise social passa a contemplar simultaneamente tanto motivações normativas quanto interesses pessoais. Já Bourdieu concebeu capital social em termos de recursos, simbólicos e materiais, provenientes do pertencimento a grupos e que podem ser manejados pelo indivíduo por meio de e em nome de relações de poder (CASTIGLIONE; VAN DETH; WOLLEB, 2008). Conforme Castiglione, Van Deth e Wolleb (2008), foi Robert Putnam o responsável por estabelecer firmemente esse conceito nos discursos acadêmico e público, aplicando-o na análise de fenômenos

\footnotetext{
${ }^{1}$ BOYD, Danah; ELLISON, Nicole. Social networks sites: definition, history, and scholarship. Journal of Computer-Mediated Communication,[S.l.], v. 13, n. 1, p. 210-230, 2007. Apud Recuero, 2009.

2 BOURDIEU, P. Le capital social: notes provisoires. Actes de la Recherche en Sciences Sociales, v. 31, p. 2-3, 1980. Apud Castiglione, Van Deth e Wolleb, 2008.

3 BOURDIEU, P. The forms of capital. In: RICHARDSON, J. G. (Org.). Handbook of theory and research for the sociology of education. New York: Greenwood, 1986. p. 241-58. Apud Castiglione, Van Deth e Wolleb, 2008.

${ }^{4}$ COLEMAN, J. S. Norms as social capital. In: RADNITZKY, G.; BERNHOLZ, P. (Ed.). Economic imperialism: the economic approach applied outside the field of economics. New York: Paragon House, 1987. Apud Castiglione, Van Deth e Wolleb, 2008.

${ }^{5}$ COLEMAN, J. S. Social capital in the creation of human capital. American Journal of Sociology, v. 94, p. 95-121, 1988. Apud Castiglione, Van Deth e Wolleb, 2008.
} 
políticos, uma vez que a confiança e a reciprocidade que emergem de redes sociais pode afetar a estrutura de uma comunidade em nível macro.

Bertolini e Bravo (20016 apud RECUERO, 2009), propõem cinco tipos de capital social em um esforço para operacionalizar esse conceito: relacional (relações, laços e trocas que conectam os indivíduos de uma determinada rede), normativo (normas de comportamento de um determinado grupo e os valores deste grupo), cognitivo (conhecimento e informações compartilhadas por um determinado conjunto), confiança no ambiente social (a confiança no comportamento de indivíduos em um determinado ambiente) e institucional (instituições formais e informais, que se constituem na estruturação geral dos grupos, onde é possível conhecer as "regras" da interação social, e onde o nível de cooperação e coordenação é bastante alto). Ainda de acordo com esses autores, os três primeiros tipos constituem capital social de primeiro nível e os dois últimos capital social de segundo nível, que, por sua vez, pressupõem a presença de pelo menos alguma dessas tipologias. Ainda quanto aos usos feitos pelos atores sociais, Recuero (2009) enfatiza que os tipos de capital social de primeiro nível podem resultar das redes de filiação (mantidas principalmente pelos sistemas), enquanto os de segundo nível seriam consequência das redes emergentes (resultantes das interações mantidas entre os atores), que demandam mais investimento por parte dos atores.

Apesar dos termos "série" e "seriado" serem usados com o mesmo sentido, Fernanda Furquim, jornalista e pesquisadora do assunto, explica que há uma diferença entre as duas expressões. De acordo com ela, os seriados têm continuidade, já que há uma trama que se desenrola a partir de vários episódios. Já as séries são fechadas, ou seja, cada episódio apresenta uma história diferente, que se sustenta por si mesma (REOLOM; GLORIA, 2010). Em uma entrevista, Fernanda Furquim (2005) aponta que sitcom é a abreviatura de Situation Comedy, ou Comédias de Situações, de modo que apenas as séries cômicas podem ser chamadas dessa forma. De acordo com ela:

0 gênero no formato que conhecemos começou no rádio, mas originou-se do teatro de variedades no qual eram apresentadas esquetes cômicas com situações do cotidiano. Quando chegou ao rádio, elas eram apresentadas em vários formatos de tempo, ou seja, de 5, 10, 15, 20 a 30 minutos. Cada semana os mesmos personagens ou personalidades viviam situações diferentes. (FURQUIM, 2005).

${ }^{6}$ BERTOLINI, S.; BRAVO, G. Social capital, a multidimensional concept. [S.l. s.n.], 2001. Apud Recuero (2009). 
Furquim (2005) afirma que a sitcom chegou à televisão na década de 50 e que algumas de suas características são utilizadas até hoje: a gravação em película (até então era ao vivo ou quando muito gravada em vídeo); a presença do público em um estúdio (muitas eram gravadas em um teatro, a exemplo do que foi feito no Brasil com Sai de Baixo), e, para isso, foi necessário adaptar o espaço para acomodar o público, que contava com um animador para manter as pessoas atentas e alegres quando eram forçados a parar por algum motivo técnico ou repetir a cena; e, a mais importante de todas, o uso de três câmeras, já que até então era utilizada apenas uma. Assim, a partir dos três conceitos apresentados (série, seriado e sitcom), percebe-se que o termo mais apropriado para The Big Bang Theory é o último.

Finalmente, em um artigo anterior (MONTARDO, 2016) propôs-se um conceito de consumo digital a partir de uma interpretação de consumo via teoria de prática (WARDE, 2005), já que se entende que tal modalidade é o que torna possível a prática da socialização online. Esse conceito foi elaborado a partir da articulação entre as ideias de consumo, performance e sites de redes sociais, de modo que consumo digital é aquele que consiste no acesso, na produção, na disponibilização e no compartilhamento de conteúdo digital na web, envolvendo ou não a alocação de recursos financeiros, desde que seja possível identificar os atores envolvidos (MONTARDO, 2016). Frente a isso, vale verificar de que forma o consumo digital configura performance no Filmow a partir de interações sobre The Big Bang Theory.

\section{Método, objeto e análise}

Quanto aos procedimentos metodológicos, esta pesquisa é de nível exploratório, pois, segundo Gil (2006), seus resultados visam proporcionar uma visão geral acerca de determinado fato, em estágio em que hipóteses precisas e operacionalizáveis são de difícil delineamento. A coleta de dados, por conseguinte, foi feita de três formas: pesquisa bibliográfica, de onde emergem as categorias de análise - consumo digital (MONTARDO, 2016), funções da performance (SCHECHNER, 2003) e capital social (BERTOLINI; BRAVO, 2001) -, pesquisa documental (descrição do site Filmow) e questionário aplicado aos usuários do Filmow/The Big Bang Theory.

A análise de conteúdo foi a técnica selecionada para análise e interpretação dos dados. De acordo com Bardin (2004), a análise de conteúdo visa analisar e buscar significações para as formas de comunicação verbal, escrita ou não escrita, estabelecidas 
entre os indivíduos. Com isso, percebe-se que esse tipo de análise cria condições para que se possa examinar, elaborar e categorizar as informações coletadas ao longo da pesquisa.

\subsection{Objeto de estudo}

Filmow é um site de rede social temático brasileiro, focado em filmes e séries, lançado no dia primeiro de abril de 2009 (FILMOW, 2014b). Seu funcionamento é livre, ou seja, qualquer internauta pode ter acesso aos comentários, avaliação e informações sobre os filmes/seriados/programas de TV. Apenas usuários cadastrados podem montar o seu perfil e desfrutar de todas as outras funções que o site oferece (FILMOW, 2014b). Suas funções incluem: compartilhar informações, avaliar, exibir uma lista dos filmes/séries/programas que já viu, quer ver, não quer ver, favoritos, comentados, além de poder marcar "Assistindo agora" e das páginas de artistas em que se pode comentar e marcar como fã.

Usuários podem cadastrar novos filmes/séries/programas de TV, de forma que, quando alguma obra é cadastrada, aparece a mensagem "aguardando confirmação". Isso significa que a página já está disponível para o público, mas ainda não passou pela "fiscalização" (PACHECO, 2012) dos seus administradores. Há também notícias, em que usuários podem curtir e comentar. No perfil, também há uma opção de dias, horas e minutos gastos em filmes assistidos (conforme o usuário for marcando os filmes como "já vi”), recados, filmes e séries favoritas, últimas opiniões enviadas, o que assistiu recentemente, amigos, fotos, filmes assistidos, o que quer ver, não quer ver, favoritos, comentados, avaliados, ídolos, listas (e listas curtidas), em que se pode adicionar filmes em listas criadas por usuários e configurá-las como públicas, privadas e somente para amigos visualizarem.

Há também algumas categorias no site, que ficam na barra direita, como procurar filmes por gêneros, filmes mais populares, artistas aniversariantes, novos usuários e últimos acessos. Além das listas contidas na página principal: estreia de filmes, filmes em cartaz nos cinemas, filmes em breve, filmes em DVD e notícias. 0 cadastro no site pode ser feito tanto como "Cadastre-se" de forma convencional, ou ser criado a partir de uma conta existente no Facebook ou no Twitter. Os usuários que optarem em integrar sua conta desse modo, podem compartilhar nesses sites seus comentários feitos nas páginas do Filmow - que também possui um aplicativo para smartphones e tablets.

The Big Bang Theory (TBBT) ou, em português, Big Bang: A Teoria, que estreiou em 2007 no canal CBS, é uma sitcom americana, do gênero comédia, criada por Bill Prady e 
Chuck Lorre. Até a conclusão desse artigo, TBBT se encontrava em sua $8^{\underline{a}}$ temporada. A emissora americana CBS diz estar satisfeita com os altos índices de audiência e pelas críticas positivas (quando a terceira temporada estreou em 21 de julho de 2009, ela alcançou o patamar de programa de maior audiência do canal), e em março de 2014 a série foi renovada até a 10 $0^{\text {a }}$ temporada (2016/2017). Com episódios curtos, com duração média de 20 minutos, a obra teve sua estreia marcada na televisão aberta no Brasil pela emissora SBT em 2011, e no dia 17 de janeiro de 2013 bateu recorde de audiência e chegou a disputar liderança com a Rede Globo, durante boa parte do tempo em que esteve no ar (THE BIG..., 2014). O SBT está atualmente exibindo a sitcom diariamente, até a terceira temporada (SBT, 2014). A série foi indicada para, e, eventualmente, conquistou, diversos prêmios, tais como: Melhor Série de Comédia e Ator em uma Série (Jim Parsons), em 2009, pela TCA Awards; Melhor Ator em Série de Comédia (Jim Parsons) pela Emmy Awards, em 2011; Programa de Comédia Favorito e Atriz Favorita de Comédia (Kaley Cuoco), pela People's Choice Awards, em 2014; Melhor Série de Comédia na 2nd Annual Fan Choice Awards, em 2014; entre tantos outros (THE BIG..., 2014). Segundo uma matéria publicada por Córdova (2014) no site Zero Hora, a empresa Nielsen apresentou dados de uma pesquisa referente à 2013/2014, em que aparece uma lista com as principais séries de sucesso nos Estados Unidos. 0 top 10 foi apresentado em dois rankings: preferidos na faixa etária entre 18 e 49 anos, e por público geral. A lista inclui apenas séries transmitidas em canais abertos da TV americana. Entre os preferidos por faixa etária, The Big Bang Theory ficou em 1o lugar. Entre o público em geral, a sitcom também conquistou o $1^{\mathrm{o}}$ lugar.

A série americana se situa em Pasadena, Califórnia, e conta a história de Leonard (Johnny Galecki) e Sheldon (Jim Parsons), dois brilhantes físicos da Caltech. Os físicos dividem um apartamento juntos e são dois nerds que têm problemas sociais (THE BIG.., 2014). A vida deles pretende mudar com a chegada de uma nova vizinha, que se muda para frente do apartamento deles, a atraente garçonete Penny (Kaley Cuoco), com quem logo criam amizade (ORANGOTAG, 2014). Mesmo com a chegada de Penny, Sheldon contenta-se em continuar passando as noites jogando com seus amigos e colegas de trabalho, Howard (Simon Helberg) e Raj (Kunal Nayyar). Mas Leonard vê nela um novo universo de possibilidades, incluindo o amor (FILMOW, 2014a). A série se desenvolve no contraste cômico entre a apresentação da "nerdice" e o intelecto puro de Leonard e Sheldon, com as habilidades sociais e o bom senso de Penny, que pode acabar ensinando a eles algumas coisas sobre a vida (THE BIG..., 2014). 


\subsection{Análise}

As postagens sobre The Big Bang Theory no Filmow, bem como as interações motivadas pelas mesmas nesse ambiente, foram analisadas no período entre a primeira postagem feita no Filmow na página da sitcom, postada em 2010, até o dia 21 de abril de 2014, data que até então seria da última postagem.

Foram contabilizadas 698 postagens, 40 delas contemplando "respostas", o que se refere à possibilidade de interação mútua neste site, e 6 delas contendo spoilers, o que é sinalizado com um recurso disponibilizado pelo sistema e utilizado por usuários que queiram ocultar informações sobre os filmes/séries.

Uma vez definido o período de análise, ou seja, todas as postagens até a data analisada, o passo seguinte foi organizar essas postagens em uma tabela para operacionalizar a análise. Nesses termos, obteve-se um documento de 142 páginas, organizado em torno das seguintes categorias de análise: consumo digital (MONTARDO, 2016); funções da performance (SCHECHNER, 2003); capital social (BERTOLINI; BRAVO, 2001).

Quanto ao tipo de consumo digital, o formato de absolutamente todas as mensagens postadas era de texto, algumas delas com links, sendo que nestas últimas identificou-se uma clara intenção de propagação de sites com os seguintes tipos de finalidades: fazer o download ou assistir a sitcom (temporadas inteiras ou episódios específicos); disponibilizar notícias, informações gerais e críticas do programa; oferecer link para assistir o episódio piloto que não foi ao ar; mostrar cenas consideradas engraçadas ou fotomontagem sobre a sitcom. Assim, com relação a essa categoria, observa-se tanto as possibilidades de postagem de quanto o acesso a informações/opiniões sobre a sitcom em questão, bem como links para baixar material do programa.

Em relação à categoria capital social, identificou-se em todas as postagens analisadas os tipos de capital social relacional e confiança no ambiente social, afinal todos os usuários entram no site para se expressarem em relação a uma mesma sitcom, que é objeto de interesse de todos os usuários que passam por ali, e o que é garantido pelos administradores do portal (que a discussão se mantenha em torno daquele tema), característica de sites de redes sociais temáticos. 0 pedido de ajuda para localizar a sitcom na Internet, bem como a indicação para assisti-la ou até alguns episódios específicos que o usuário julgue interessante, demonstram de forma mais evidente a ocorrência de capital social de segundo nível, aconfiança no ambiente social. 
Ainda com relação à essência de um site de rede social temático, todas as postagens analisadas cumprem as funções da performance "marcar ou mudar a identidade", bem como "fazer ou mudar uma comunidade", conforme Schechner (2003). Percebe-se, quanto a isso, que a maior parte das mensagens combina um componente relacional com cognitivo em termos de capital social, ao expressar uma opinião sobre a sitcom, bem como informações sobre a mesma. Nesses casos, observou-se, também, a ocorrência da função da performance em "ensinar, persuadir ou convencer"(SCHECHNER, 2003).

O motivo pelo qual se observa a alocação de capital social relacional e confiança no ambiente social, bem como duas funções de performance de modo permanente em todas as postagens deve-se ao fato de que todas elas se referem especificamente à sitcom ou a temas correlatos (nerds, física, outras séries de comédia, etc.). Do uso do recurso de alerta a spoilers, o que configura alocação de capital social normativo em seis postagens, depreendese o interesse em atrair novos usuários para o espaço, bem como de preservar a função do mesmo (informações e opiniões sobre a sitcom, sem estragar a surpresa de quem ainda não assistiu a um determinado episódio).

Em termos de conteúdo postado, das 698 postagens analisadas, 410 consistem em opinião positiva, 262 são opinião neutra/comentário geral/citação/informação sem link, 18 são opiniões negativas e 8 são piadas/opinião positiva. Entre as 262 opiniões neutras/comentários gerais/citações/informações sem link, incluem-se cerca de 50 postagens com a citação "Bazinga", muitas com o famoso "Toc toc toc, Penny, Toc toc toc, Penny, Toc toc toc, Penny", e, ainda, outras expressando o amor pelos personagens, principalmente pelo protagonista Sheldon, além de comentários relatando alguma cena ou episódio específico, ou de postagens de usuários que apreciam a sitcom e se expressaram da seguinte forma: "a física só é engraçada e legal em the big bang theory q", "Adoroooo! (Embora tenha assistido só 4 episódios)"; "Só observando", entre outras.

Percebeu-se, também, que a página analisada (da primeira temporada) parece servir como uma referência para enviar novos comentários, visto que termos como "Bazinga", palavra inventada na sitcom pelo personagem Sheldon (Jim Parsons), só aparecem na segunda temporada, e não na primeira, quando os comentários já são vistos.

Outro ponto interessante a ser comentado é que a primeira temporada estreou em 2007, e, mesmo em 2014, ainda havia comentários recentes, próximos à data analisada, sendo postados, mesmo que houvesse a oportunidade de fazê-lo em páginas de temporadas mais recentes. Pode-se dizer, então, que os usuários se apropriaram da página da primeira 
temporada para comentários gerais, talvez pelo fato de que o Filmow, mesmo sendo um site de rede social e também possuir em seu catálogo séries, seriados, novelas, etc., não foi inicialmente pensado para isso, visto que o foco principal são os filmes, que, diferentemente das ficções seriadas, não precisam de uma parte do site com marcações de episódios e temporadas. Hoje no Filmow, só pode marcar como "Já vi" a temporada inteira, e não apenas alguns episódios, diferente de outros espaços projetados apenas para isso (séries e seriados), como o caso do site de rede social temático Orangotag (c2013), em que se pode marcar a temporada, mas também um episódio por vez. Localizou-se um comentário que se posicionou em relação a isso, de forma negativa, sobre o Filmow: "A série é ótima! Mas eu acho tosco poder colocar séries no "filmow..."”.

Observou-se também, que frente a opiniões negativas, os usuários defendem a sitcom em resposta a esses usuários, insinuando que os mesmos não entenderam as piadas e que, por isso, não gostaram ou acharam graça nas mesmas: "Se não entende oq querem dizer realmente fica difícil de achar graça!", "entender as piadas seria um bom começo né? se não gosta, não assiste. Ponto", "Humor inteligente é assim mesmo. não é qualquer um que entende. BAZINGAAAAAAAAAAAAAAAA! Sheldon s2".

Interessante é notar a falta de tolerância quanto a quem tem opiniões diferentes da maioria dos usuários, como também demonstra a seguinte postagem: "Odeio pessoas efusivas e pseudo-cults, que reclamam de algo pra si e consequentemente querem mostrar isso pra todo mundo. Por favor, só comenta quem gosta, simples e prático.". Em resposta a isso, outro usuário o apoiou: "Verdade. Criticar algo que 99\% dos comentaristas aprovam não vai fazer diferença. E para quem não gosta do TBBT eu digo: BAZINGAAAAAAA!!!!!". Tudo isso parece indicar que aquele espaço/página é apropriado principalmente pelos apaixonados pela sitcom.

\subsection{Usos do Filmow para fãs e outros usuários de The Big Bang Theory}

0 questionário teve como objetivo entender as motivações para os usos do site Filmow em relação a séries e à sitcom TBBT. 0 questionário foi composto de 17 questões e enviado somente para usuários do site que tenham assistido a The Big Bang Theory, ou seja, foi enviado para usuários que tenham comentado/visto pelo menos uma temporada da sitcom entre a 1 a e 8 a $^{-}$temporada e marcado nas páginas de temporadas da sitcom no Filmow, entre os dias 17 de março e 08 de abril de 2015. Foram obtidas 89 respostas. 
Com mais de uma possibilidade de marcação de resposta, sobre as motivações para o uso do Filmow, 88.8\% (79) dos fãs responderam organizar os filmes/séries como assistidos, favoritos, quero ver, etc.; 77.5\% (69), ter acesso à opinião de outros usuários sobre filmes e séries; 76.4\% (68), descobrir filmes/séries que sejam do seu gosto; $75.3 \%$ (67), ter acesso a informações sobre filmes e séries; 73\% (65), opinar sobre filmes e séries; $33.7 \%$ (30) ter acesso a informações sobre artistas; $24.7 \%$ (22) organizar os seus filmes/séries por listas; 3.4\% (3) responderam a opção "outros", entre os quais, interação com usuários brasileiros. Pode-se notar que a interação entre os usuários do site se concentra em organizar o ato de assistir a série, opinar e se informar sobre possíveis novas séries. Nas palavras de um respondente: "Agora, quando eu comento é mais para eu me situar e não para receber resposta (se serve de ajuda para alguém não é o que busco).”.

Com relação aos recursos que o usuário mais utiliza no Filmow, 93.3\% (83) respondeu para avaliar um filme/série (atribuição de estrelinhas); empatadas com 79.8\% (71) foram marcadas as opções escrever um comentário e marcar o andamento em que assiste aos filmes/séries (vou ver, já vi, não quero ver); 74.2\% (66) marcar filme/série como favorito, já vi 1,2,3,4,5 vezes, etc.; 53.9\% (48) responder a um comentário; 25.8\% (23) indicar filme/série para os seus amigos; 24.7\% (22) criar suas próprias listas; $21.3 \%$ (19), para cadastro de filme/série; e 2.2\% (2) responderam a opção "outros", como, por exemplo, interagir com usuários. Frente a isso, evidencia-se uma situação em que motivações individuais guiam as ações dos usuários em relação às séries, com destaque para a avalição automática dos filmes, comentários e marcação de andamento de acompanhamento das séries e marcação de favoritos.

Quando perguntados sobre já terem assistido um filme/série influenciado pelo Filmow, questão em que era possível marcar mais de uma opção, 77.5\% (69) responderam que sim, devido à boa avaliação (estrelinhas) do filme/série; 68.5\% (61) sim, devido aos comentários com críticas positivas sobre o filme/série; 11.2\% (10) responderam não; 7.9\% (7) sim, devido ao grande número de pessoas que marcaram em "Já vi" o filme/série; 4.5\% (4) sim, devido ao grande número de pessoas que marcaram em "Quero ver" o filme/série; e 6.7\% (6) responderam a opção "outros", como "Indicação dos próprios usuários do Filmow". Percebe-se, aqui, que a avaliação automática é preferida em relação à leitura de críticas sobre as séries como fator de influência de consumo.

Em questão na qual era possível marcar mais de uma opção como resposta, questionou-se sobre o fato de já ter deixado de assistir um filme/série influenciado pelo 
Filmow. Foram 49.4\% (44) respostas negativas; 46.1\% (41) positivas, devido aos comentários com críticas negativas sobre o filme/série; 31.5\% (28) sim, devido à baixa avaliação (estrelinhas) do filme/série; com 2.2\% (2) vieram empatadas as opções sim, devido ao grande número de pessoas que marcaram em "Não quero ver" o filme/série e a opção "outras": "Já deixei de ver por ter lido um spoiler desavisadamente. E isso ocorreu várias vezes.". Fica claro, aqui, que quanto a não assistir a um produto audiovisual, os comentários são mais decisivos do que as avaliações automáticas, e que problemas com spoilers parecem ser frequentes e também influenciam no abandono da ideia de acompanhar uma série, referindo uma falta de alocação de capital social normativo e institucional por parte dos usuários.

A quarta, e última parte, foi sobre o uso da(s) página(s) da sitcom The Big Bang Theory no Filmow. A pergunta número 15 foi: Você já deixou de assistir ou abandonou a série por um tempo por conta de comentários negativos de outros usuários?, 95.5\% (85) responderam que não; 1.1\% (1) respondeu que sim; e 3.4\% (3) responderam a alternativa “outras”: “Não, pois já conhecia a sitcom.”; “Não. A série em si me fez abandoná-la”. Já 78.7\% (70) responderam que não assistiram novamente um episódio devido a comentários positivos. Quanto a isso, um respondente explicou: "Só os simpsons (quando tem coisas diferentes) de resto pouco me importa os comentários alheios". Pode-se dizer que essas duas últimas questões reforçam as motivações individuais de uso do espaço indicadas anteriormente (organizar o acompanhamento de uma série, opinar e se informar sobre a mesma), de modo que, ao menos alguns usuários, não têm interesse no que as pessoas pensam sobre a sitcom.

Quando perguntados "Você percebe uma certa repreensão por parte de outros usuários quando fazem comentários negativos sobre a sitcom?", 42.7\% (38) responderam que sim; 37.1\% (33) nunca repararam; 14.6\% (13) responderam que não; e 5.6\% (5) marcaram a alternativa "outros": "Claro que sim. Infelizmente tem besta em tudo quanto é lugar na net". Essas respostas podem indicar um comportamento de fã por parte dos usuários, de que se frequenta um espaço com uma expectativa unicamente positiva sobre um produto audiovisual e que se despreza uma opinião diferente desta.

Uma questão interessante é a de que, quando se pergunta aos usuários se consideram a página da primeira temporada como uma página "oficial" para se fazer comentários em geral, já que o Filmow não dispõe de página independente das temporadas para uma sitcom, 49.4\% responderam que não. No entanto, a expressão "Bazinga", palavra 
inventada pelo personagem Sheldon e que só aparece no último episódio da segunda temporada, consta na página da primeira temporada. Ainda quanto a isso, questionados sobre terem assistido duas, três ou mais temporadas de uma série e voltar a comentar na página da primeira, 55.1\% responderam que não o fazem. Isso parece demonstrar que, em uma sitcom, talvez o aspecto sequencial da narrativa não importe tanto quanto em um seriado, conforme indica o seu conceito.

Outra questão que dificultou foi um bloqueio pelo site, contra spam, que somente permitia o envio de um comentário por vez, em um período de quinze em quinze minutos. Essa experiência foi diferente da análise do Skoob (MONTARDO; SILVA, 2015a), em que, na época de sua aplicação (2013), era possível enviar cerca de 30 comentários até ser bloqueado (e assim esperar para enviar mais). Ainda quanto a isso, verificou-se que, em algumas páginas de temporadas, havia muitos comentários antigos (seis meses anteriores à data de envio do link do questionário), mesmo entre os vinte mais recentes. E muitos usuários "repetidos", em que quando ia enviar o link, descobria-se no perfil que já havia sido enviado antes, por conta de ter visto o perfil com comentário em outra página de temporada. Esses pontos também podem justificar o número menor de respondentes (89) em relação ao questionário do Skoob (251).

\section{Considerações finais}

Três pontos principais devem ser retomados a título de considerações finais. Em primeiro lugar, destaca-se a semelhança entre os resultados obtidos com esta análise e os obtidos quanto às interações em torno do filme 12 anos de escravidão (2014) também no Filmow (MONTARDO SILVA, 2015b). Por outras palavras, as funções da performance associadas à identidade e à comunidade, bem como tipos de capital social (relacional e confiança no ambiente social) são localizadas em todas as manifestações dos usuários no espaço analisado, garantindo-se que as interações se restringissem ao tema discutido (The Big Bang Theory). Da mesma forma que, naquele estudo, observaram-se poucas interações mútuas por meio de respostas, o que parece sugerir que o espaço em que se interage possa ser mais importante do que o tema em torno do qual se empreendem as interações quando se trata, pelo menos, de sites de redes sociais temáticos voltados a produtos audiovisuais. Isso porque 12 anos de escravidão (2014), filme vencedor do Oscar 2014, em tudo difere de The Big Bang Theory: em formato (um é filme, o outro é sitcom; um tem 135 minutos, o 
outro, oito temporadas com número de episódios variados cada), em tema (um é mainstream - vencedor de Oscar ao tratar de uma questão humanitária universal, a escravidão, o que parece lhe garantir alcance considerável entre as audiências; o outro, mais voltado para nicho subcultural - nerds). Porém, os dois foram objetos de conversação no mesmo site de rede social temático, Filmow, condição que parece apontar para a ocorrência de certos comportamentos em termos de performance nesses espaços, independente do objeto de discussão.

Um segundo ponto é que, ao que tudo indica, o Filmow foi feito para suportar discussões sobre filmes e não sobre séries e sitcoms. Isso porque, diferente de outros espaços destinados ao mesmo fim (Orangotag), Filmow permite a avaliação apenas da série inteira e não de seus episódios específicos, o que fica evidente com a questão de a primeira temporada servir ou não para centralizar comentários gerais sobre a sitcom. Essa questão técnica respingou na dificuldade encontrada quanto à postagem de questionários no canal do Filmow sobre The Big Bang Theory relativos a diferentes temporadas, o que forçava uma espera a cada 15 minutos para tanto, e que resultou, também, na presença de comentários dos mesmos usuários nos diferentes canais voltados para cada temporada da sitcom. Ou seja, alguns usuários se depararam diversas vezes com o mesmo questionário postado.

Finalmente, um terceiro ponto refere-se ao fato de que se pode afirmar que, em sites de redes sociais temáticos sobre produtos audiovisuais, parece haver uma inversão quanto ao que propõe Recuero (2009), uma vez que, em nossa análise, os tipos de capital social de primeiro nível (cognitivo, relacional e normativo) provém da ação entre os usuários do site (relações emergentes), enquanto que os de segundo nível (confiança no ambiente social e institucional) são fortemente influenciados pelo sistema que suporta as interações, e pela ação dos administradores do site. Disso se apreende, por exemplo, que confiança no ambiente social seja, em grande parte, garantida pelo fato de se tratar de um site projetado para se restringir a um determinado tema. Resultados semelhantes a esse foram encontrados em análises de conversações mediadas em torno de temas específicos em páginas e grupos no Facebook, em comunidades do Orkut, e, também, em alguns tipos de jogos online (FRAGOSO, 2006, 2008, 2015). Importante ressaltar que, mesmo assim, identificam-se iniciativas de emergência por parte dos usuários, como, por exemplo, atuarem no sentido de assegurar o mínimo de divergência de gostos quanto aos temas debatidos. Pode decorrer dessa situação a apropriação dos usuários do site em termos de motivações individuais para o seu uso (marcar andamento de acompanhamento de 
séries/filmes/sitcoms, opinar e se informar sobre filmes), no que se percebe uma forte relação entre os recursos disponíveis por um dado site e a performance possível no mesmo.

\section{Referências}

12 ANOS de Escravidão. Direção: Steve McQueen. [S.l.: s.n.], 2014.

BARBOSA, Lívia. O estudo do consumo nas ciências sociais contemporâneas. In: BARBOSA, Lívia; CAMPBELL, Colin (Org.). Cultura, consumo e identidade. Rio de Janeiro: FGV, 2009.

BARDIN, Laurence. Análise de conteúdo. Lisboa: Edições 70, 2004.

BOYD, Dannah. "Why youth (heart) social network sites: the role of networked publics in teenage social life." Cambridge: MIT Press, 2007. MacArthur Foundation Series on Digital Learning - Youth, Identity, and Digital Media Volume.

CAMPBELL, Colin. Eu compro, logo sei que existo: as bases metafísicas do consumo moderno. In: BARBOSA, Lívia; CAMPBELL, Colin (Org.). Cultura, consumo e identidade. Rio de Janeiro: FGV, 2009.

CASTIGLIONE, Dario; VAN DETH, Jan; WOLLEB, Guglielmo (Ed.). The handbook of social capital. Nova York: Oxford University, 2008.

CÓRDOVA, Nathalie. Lista: as dez séries com maior audiência nos Estados Unidos. Zero Hora, Porto Alegre, 30 maio 2014. Kzuka. Disponível em:

<http://zh.clicrbs.com.br/rs/noticia/2014/05/lista-as-dez-series-com-maior-audiencianos-estados-unidos-4513896.html>. Acesso em: 18 jun. 2014.

EHRENBERG, Alain. 0 culto da performance: da aventura empreendedora à depressão nervosa. Aparecida: Ideias \& Letras, 2010.

FILMOW. [S.l., 2014a]. Disponível em: <http://filmow.com>. Acesso em: 12 nov. 2014.

FILMOW. In: Wikipédia: a enciclopédia livre. [S.l.]: Wikimedia, 2014b. Disponível em: <http://pt.wikipedia.org/wiki/Filmow>. Acesso em: 2 jul. 2014.

FRAGOSO, Suely. Conectibilidade e geografia em sites de rede social: um olhar sobre as relações entre território e identidade a partir do Orkut. Galáxia, São Paulo, n. 16, p. 109122, 2008.

FRAGOSO, Suely. Eu odeio quem odeia... considerações sobre o comportamento dos usuários brasileiros na tomada do Orkut. E-Compós, Brasília, v. 6, p. 1-22, 2006.

FRAGOSO, Suely. 'HUEHUEHUE eu sou BR': spam, trollagem e griefing nos jogos online.

Revista FAMECOS, Porto Alegre, v. 22, p. 129-146, 2015. 
FURQUIM, Fernanda. Entrevista com a jornalista Fernanda Furquim, sobre séries de TV. 2005. Disponível em: <http://www.poucaseboasdamari.com/2005/12/entrevistafernanda-furquim-series-de-tv/>. Acesso em: 19 nov. 2014.

GOFFMAN, Erving. A representação do eu na vida cotidiana. Petrópolis: Vozes, 1975.

GIL, Antônio Carlos. Métodos e técnicas de pesquisa social. São Paulo: Atlas, 2006.

MONTARDO, Sandra Portella. Consumo digital e teoria de prática: uma abordagem possível. Revista Famecos, Porto Alegre, v. 23, n. 2, 2016. Disponível em:

<http://revistaseletronicas.pucrs.br/ojs/index.php/revistafamecos/article/view/22203>. Acesso em: 3 abr. 2017.

MONTARDO, Sandra Portella; SILVA, Thaís Della Tôrres da. Consumo digital, performance e livros: estudo comparativo entre os sites Skoob e Scribd. Revista Fronteiras: Estudos Midiáticos, São Leopoldo, v. 17, n. 1, p. 23-32, jan./abr. 2015a. Disponível em: $<$ http://revistas.unisinos.br/index.php/fronteiras/article/view/fem.2015.171.03>. Data do acesso: 03/04/2017.

MONTARDO, Sandra Portella; SILVA, Thaís Della Tôrres. Contém spoiler. Performance e Consumo no SRS temático Filmow. Revista Alceu, Rio de Janeiro, v. 15, n. 30, p. 117-133, 2015b. Disponível em: <http://revistaalceu.com.pucrio.br/cgi/cgilua.exe/sys/start.htm?from\%5Finfo\%5Findex=9\&infoid=537\&sid=42>. Acesso em: 3 abr. 2017.

NASCIMENTO, Lilian. Exposição e performance em sites de rede sociais. In: SIMPÓSIO NACIONAL DA ASSOCIAÇÃO BRASILEIRA DE PESQUISADORES EM CIBERCULTURA, 4., 2010, Rio de Janeiro. Anais... Rio de Janeiro: ABCiber, 2010. p. 1-15.

ORANGOTAG. Disponível em: <http://orangotag.com/>. C2013. Acesso em: 17 jun. 2014.

PACHECO, Natália. Redes sociais para geeks. 2012. Disponível em: <http://www.vireapagina.com/2012/05/redes-sociais-para-geeks.html>. Acesso em: 2 jul. 2014.

PINHEIRO, Marta de Araújo. Subjetivação e consumo em sites de relacionamento.

Comunicação, Mídia e Consumo, São Paulo, v. 5, n. 14, p.103-121, 2008.

RECUERO, Raquel. Redes sociais na internet. Porto Alegre: Sulina, 2009.

REOLOM, Mônica; GLORIA, Rafael. Séries \& Seriados: uma trama universal. Jornal do Comércio, Porto Alegre, 21 maio 2010. Disponível em:

<http://jcrs.uol.com.br/site/noticia.php?codn=28784>. Acesso em: 19 nov. 2014.

SBT. Big Bang: a teoria. 2014. Disponível em:

<http://www.sbt.com.br/series/bigbang/episodios/>. Acesso em: 28 abr. 2015.

SCHECHNER, Richard. 0 que é performance. 0 Percevejo, Rio de Janeiro, v. 11, n. 12, p. 110, 2003. 
THE BIG Bang Theory. In: Wikipédia: a enciclopédia livre. [S.I.]: Wikimedia, 2014.

Disponível em: <http://pt.wikipedia.org/wiki/The_Big_Bang_Theory>. Acesso em : 17 jun. 2014.

WARDE, Alan. Consumption and theories of practice. Journal of Consumer Culture, [S.I.], v. 5, n. 2, p. 131-153, 2005. Disponível em:

<http://www.espm.br/Pesquisadores_versao1/CAEPM/Documents/Consumption\%20and \%20Theories\%20of\%20Practice.pdf>. Acesso em: 4 fev. 2013.

\title{
Bazinga! Consumption and performance on The Big Bang Theory on Filmow
}

\begin{abstract}
This article aims to identify consumption as a performance of The Big Bang Theory sitcom on Filmow, a thematic social network website for movies and series lovers. For this purpose, the theoretical background approaches the relations among the three analysis categories selected for this study: digital consumption, performance and thematic social network websites. Regarding methodology, this research consists of an exploratory level, through both bibliografphical and documental survey and the application of questionnaires to the users. Starting from the analysis of 698 comments of users of the sitcom page, one has noticed that, different from what is usually observed in general social network websites, Filmow's structure seems to assure social capital allocation on the second level (trust in social and institutional environment) instead of the kinds of social capital of first level (cognitive, relational and normative), which comes from the interactions among users in this case.
\end{abstract}

\section{Keywords}

Digital consumption. Performance. Social capital. Filmow. The Big Bang Theory.

Recebido em 11/07/2016

Aceito em 20/10/2016 